almost 20 hours to present evidence at the hearings and is bringing a number of scientists from Europe.

OSHA, emphasising the uncertainty that surrounds the interpretation of current scientific findings about carcinogenicity, has stated that, for the purposes of policy, it is basing its proposals on a number of propositions. The basic philosophy-a philosophy close to the heart of OSHA's director Dr Eula Bingham, until last year year professor of environmental health at the University of Cincinnati Medical School-is that where uncertainty exists, the prime concern is to protect the health of the worker.

Thus the administration claims that, given the lack of any conclusive evidence for a "threshold" below which carcinogenic effects can be ignored, any attempt at precise risk assessment at low level is unlikely to produce reliable results. It is therefore suggesting that exposure levels should be reduced "as low as feasible".

Similarly, OSHA states that because of the difficulties and limitations of human epidemiological studies-and the moral arguments against waiting for demonstrable proof of carcinogenicity from these studies-in general "as a practical rather than a theoretical matter, positive animal data should supersede negative human data".

Concerning the interpretation of evidence that a substance may cause only benign, rather than malignant, tumours, OSHA again comes down on the side of caution. It proposes "to place as much weight on an experiment in which only benign tumours are observed, as upon experiments in which both are induced."

In contrast to this approach, industry is arguing that the only "rational" basis for regulation should be firmly established scientific knowledge, which would include quantifiable parameters such as the relative potency of different carcinogens, and that such knowledge is a pre-requisite for regulation. Thus the lack of evidence for a threshold is interpreted as lack of evidence that no threshold exists, casting doubts on any regulatory principle based on the latter hypothesis. "No-effect levels have been repeatedly demonstrated for carcinogens in animals and man", claims Dr Hoerger of Dow Chemicals, chairman of AIHC's scientific committee.

And in questioning OSHA's proposal to give greater weighting to animal than human studies, the AIHC says that "since human epidemiological data are free from the uncertainties of extrapolation from animal tests, it seems quite unscientific not to use the data when available".

There are similar differences of approach over short-term tests, such as those for mutagenicity developed by

\title{
US firms accused of exporting health hazards
}

INCREASINGLY stringent control of hazardous production processes appears to be leading US companies to switch the work to countries with lower safety standards, pariicularly in the Third World.

In a number of industries, the banning of certain processes in the US has been followed by a significant increase in the import of materials made by these processes (in the case of benzidine dyes, for example, principally from Romania, Poland, India and France). And in other industries. American companies are shifting their own facilities elsewhere.

Some of the more dramatic examples of 'hazard export' have come from the asbestos industry. At least one study of the effects of lowering exposure levels to US workers has concluded that this is economically feasible provided that some of the more hazardous operations are conducted outside the US.

The import of asbestos textiles, for example, has risen dramatically in recent years from countries such as Mexico, Taiwan and Brazil as home

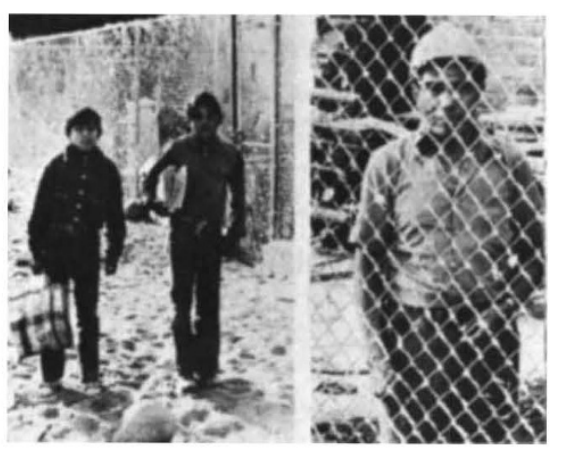

Photographs taken by Dr Johnson outside Amatex asbestos textile plant, Agua Prieta, Mexico. March 1977.

producers have experienced the need to meet lower levels of exposure.

Many of the production facilities are American-owned (although Japan owns plants in Taiwan and South Korea). And although most asbestos companies are careful to maintain the same safety standards at home and abroad, this is not always achieved.

Last year, for example, an environmental health scientist from Washington Siate University, Dr William M. Johnson, reported having found large quantities of loose asbestos both inside and outside a textile plant that had been opened by a large American-owned asbestos company in the Mexican border town of Agua Prieta in 1969.

Following the publicity surrounding his report, workers have been required to wear uniforms to cover street clothes, and the outside of the factory has been regularly cleaned. However, on revisiting the plant $\mathrm{Dr}$ Johnson claimed that the effects were mainly "cosmetic", and that the ground outside the factory on which children frequently played, for example, was still composed of $20 \%$ asbestos (see picture left).

Such situations are causing considerable concern to officials of the Ozcupational Safety and Health Administration (OSHA). "Cancer knows no national boundaries," says Dr Joseph Wagoner, head of carcinogens at OSHA.

US officials are uncertain about how to proceed. Working conditions outside the US are beyond the direct control of Washington; and many countries openly express a willingness to accept new jobs-however hazardous - because of unemployment problems. David Dickson

Dr Bruce Ames of the University of California. Here the uncertainty arises from the fact that, although the correlation between the mutagenicity and the carcinogenicity of a substance is close, it is far from perfect.

OSHA, accepting this uncertainty as the grounds for suggesting that such tests should not be used as a sole basis for identifying carcinogenic potential, nevertheless feels they are sufficiently reliable to corroborate evidence of carcinogenicity gained from one animal test. Industry interprets this uncertainty in the opposite direction. Accepting that short-term tests have values as screening tools and as guides for more complete tests and studies, the AIHC adds that "the results of such tests are so unreliable as predictors of human response as to be unsuitable as a basis for regulatory decisions".

Much of the public hearing which started last week, and will continue until the middle of July, is expected to hinge on such differences of interpretation of evidence in areas of scientific uncertainty, But in practice, although minor changes may be made to the details of OSHA's proposals, few expect any major shift in philosophy.

The real test, however, is likely to come later in the courts, where the issues will be determined not so much on scientific as on procedural ground. OSHA has already - experienced difficulty here. Current moves to regulate benzene, for example, have come under heavy legal fire. The carcinogen proposals are one pudding whose proof will be the eating. 